\title{
The Link Between Psychosis and Creativity: A Myth or a Reality?
}

\author{
Teresa Sousa-Ferreira \\ Centro Hospitalar Tâmega e Sousa, \\ Penafiel, Portugal
}

\author{
Maria do Céu Ferreira \\ Hospital de Braga, \\ Braga, Portugal
}

\author{
Sérgio Ferreira \\ Centro Hospitalar Tâmega e Sousa, \\ Penafiel, Portugal
}

\begin{abstract}
Introduction: Creativity is a positive human characteristic and considered the basis of many human conquers in various fields of knowledge. The hypothetical relationship between creativity and psychiatric vulnerability was first debated in antiquity and since then the plot thickens even more. From the last century, creativity and psychopathology became even more spoken due to the artworks created by mentally affected artists. Although some results have suggested a relationship between creativity and psychosis, few studies have examined this relationship using empirical methods. For this reason, the possible association between the two issues is considered one of the most controversial topics nowadays. Aim: The aim of this article is to present a literature review of the putative link that are being studied between creativity and psychosis and the main outcomes available so far. Methods: Literature review of selected article deemed relevant by the authors, using Medline/Pubmed database with the combination of the following keywords: "creativity", "psychosis", "psychopathology" with no time limits of publication. References of the selected articles were also considered. Results and Conclusions: A connection between creativity and psychopathology in what concerns to bipolar disorder, schizophrenic disorder as well as squizotypal disorder, as been suggested by the ongoing research on the fields of biology, imagiology, genetic as well as psychometric and psychodiagnostic (mainly the last two). Nevertheless, comparison between studies is difficult due to different definitions and methods used. Besides there is also a need for integration of findings in the different research areas mentioned, in order to reach more accurate conclusions.
\end{abstract}

Keywords: creativity, psychosis, psychopathology

\section{Introduction}

Creativity is a positive human characteristic and considered the basis of many human conquers in various fields of knowledge. The hypothetical relationship between creativity and psychiatric vulnerability was first debated in antiquity and since then the plot thickens even more.

From the last century, creativity and psychopathology became even more spoken due to the artworks created by mentally affected artists (Thys, Sabbe, \& De Hert, 2012). In addition, the reports of creative people who suffered from mental disorders were increasing, which lead some authors to the thought that "...madness may be the price for possessing one of the most sublime human gifts (Barrantes-Vidal, 2004)".

Teresa Sousa-Ferreira, Psychiatry Resident, Departament of Psychiatry and Mental Health, Centro Hospitalar Tâmega e Sousa. Maria do Céu Ferreira, Psychiatry Resident, Departament of Psychiatry, Hospital de Braga.

Sérgio Ferreira, Psychiatry Assistant, Departament of Psychiatry and Mental Health, Centro Hospitalar Tâmega e Sousa. 
Some large sample sized epidemiological studies confirmed an association between creative professions and first-degree relatives of patients with schizophrenia, bipolar disorder, anorexia nervosa, and for siblings of patients with autism (Kyaga, Landén, Boman, Hultman, Långström, \& Lichtenstein, 2013).

Some authors have suggested that mood disorders could be correlated to creativity, mainly thought biographical and interview-based research (Jamison, 1989; Andreasen, 1987). Although they have shown some evidence of that relationship, these outcomes are considered limited. In what concerns to psychosis and its putative link with creativity, very few studies, using empirical methods were performed, in order to reach solid conclusions (Fink, Benedek, Unterrainer, Papousek, \& Weiss, 2014; Barrantes-Vidal, 2014).

For this reason, the possible association between psychosis and creativity is considered one of the most controversial topics.

\section{Aims}

The aim of this article is to present a literature review of the putative link, that is being studied, between creativity and psychosis and the main outcomes available so far.

\section{Methods}

A literature review of selected article deemed relevant by the authors was performed, using Medline/Pubmed database with the combination of the following keywords: "creativity", "psychosis", "psychopathology". There were no time limits of publication. It was obtained 127 articles. Thirty nine articles from that search were used. The remaining articles were not directly related to the topic. References of the selected articles were also considered.

\section{Creativity}

The study of relevant articles obtained showed that have been difficulties in the definition and measurability of creativity among the available literature.

Creativity emerged as an adaptive cognitive mechanism for low frequency, "improvisational reasoning", where solutions to problems are unsighted and probabilistic approximation could lead to novel solutions (Simonton, 2013). The concept of creativity is being differentiated from the concept of intelligence, on which, the latter supplies a "dedicated reasoning capacity" for problems that possess rule-based, cause-effect relationships (Jung, 2014).

It is considered that creative thinking process has DT (the divergent thinking) as a valid core element (Bartlett \& Davis, 1974; Torrance, 1988). On one hand, Guilford (1959) has emphasized DT as a use of flexible responses that elaborate upon an existing idea (Guilford, 1959). On the other hand, Mednick (1962) built his definition upon Guilford's, stating that creative thinking emphasizes also generating novel associations (Mednick, 1962).

\section{Main Research Pathways}

We have found four main domains on which research about the association between creativity and psychosis is been conducted: psychometric and psychodiagnostic research, imagiology, biology and also genetic research (Thys, Sabbe, \& de Hert, 2011).

\section{Psychometric and Psychodiagnostic Research}

Psychometric and psychodiagnostic research supports a link between creativity and the psychopathology of bipolar, schizophrenic and especially schizotypal disorder (Thys et al., 2011). 
Schizotypy, is a complex personality trait composed by four factors, such as unusual experiences (hallucinations, magical or superstitious belief and interpretation of events), cognitive disorganization (a tendency for thoughts to become disorganized or tangential), introverted anhedonia (a tendency to introverted, emotionally flat and asocial behavior, with a deficient ability to feel pleasure from social and physical stimulation) and impulsive nonconformity (the disposition to unstable mood and behavior particularly with regard to rules) (Claridge \& Blakey, 2009). There is overwhelming support for a positive relationship between creativity and schizotypy (Abraham, Windmann, Daum, \& Güntürkün, 2005; Acar \& Runco, 2012; Fink, Slamar-Halbedl, Unterrainer, \& Weiss, 2012). Some aspects of schizotypy, like unusual experiences may be linked to psychometrically determined creativity (Claridge \& Blakey, 2009); Elevated levels of schizotypy were also found in samples of artists with creativity psychometrically determined (Nelson \& Rawlings, 2010). It is known that schizotypy increase the vulnerability of psychotic disorder (Nettle, 2006).

Historical and biographical data do suggest that the relationship between creativity and pathology in schizophrenia is strongest among healthy first degree relatives compared to the affected individuals themselves (Karlsson, 1984). Besides, significant relationships between relatives of schizophrenic patients and employment in highly creative professions have been found (Juda, 1949; Karlsson, 1970; Karlsson, 2001). These results suggest that high creativity may be masked by the psychotic symptoms in schizophrenics but can be detected in those individuals who share a latent liability for psychosis.

In what concerns to bipolar disorder, the research taken by Jamison $(1989 ; 1995)$ provided evidence that it is the depressive period of bipolar cycling that contributes to the initiation of creative ideas, and then these ideas are combined with others during the manic fases leading to episodes of extreme creativity (Jamison, 1989; 1995).

\section{Imaging Techniques Research}

The idea that similar mental process may be implicated in creativity as well as in psychosis-proneness has also received some support from the imaging techniques research.

Schizophrenia is associated with reduced functional and structural laterality and increased hemispheric interactions (Bekhtereva, Starchenko, Klyucharev, Vorob'ev, Pakhomov, \& Medvedev, 2000; Carlsson, Wendt, \& Risberg, 2000). It has been argued that reduced hemispheric dominance is also central to creativity thinking (Claridge \& Broks, 1984).

Functional magnetic resonance imaging showed that creativity and schizotypy were alike in terms of similar functional brain activity patterns during creative ideation, where a reduced deactivation of right parietal brain regions and the precuneus were verified (Fink et al., 2014).

Folley and Park using behavioral and NIRS (near-infrared optical spectroscopy) methods suggested that schizotypy is associated with enhanced divergent thinking and both were associated with the use of bilateral prefrontal cortex. They have also suggested that schizotypes, who have enhanced creative thinking ability, use mainly the right prefrontal cortex compared to schizophrenics and controls (Folley \& Park, 2005).

Thanks to the use of FA (Fractional Anisotropy), it was demonstrated a potential overlap between the neural substrates of both creative cognition and psychosis. Jung and collegues, with their Investigations on white matter integrity, reported that lower levels of FA in the anterior thalamic radiation were associated with 
higher divergent thinking performance in a sample of young healthy adults (Jung, Grazioplene, Caprihan, Chavez, \& Haier, 2010). Reduced FA in the anterior thalamic radiation (Haznedar et al., 2005; Sussmann, Lymer, McKirdy, Moorhead, Maniega, \& Job, 2009) and uncinate fasciculus (McIntosh et al., 2008) within frontal brain regions were also found in schizophrenic and bipolar patients.

Sussmann (2009) in persons with schizotypal personality disorder, observed reduced FA within the uncinate fasciculus, providing strong support for the hypothesis that similar neural phenotypes may not result in the same clinical symptoms (Sussmann et al., 2009).

These findings are consistent with the idea of a continuum once they suggest an association between specific white matter architecture underlying the normal variance of divergent thinking and psychotic-spectrum traits (Jung et al., 2010).

\section{Biologic Research}

Biologic research has been studying the role of membrane phospholipid metabolism and NE (the norepinephrine) system in the potential relationship between creativity and psychosis. It has been suggested that NE levels are decreased in high creative states on healthy individuals as well as in the first-degree relatives of schizophrenic patients (Horrobin, 1998; Wei, Ramchand, \& Hemmings, 1992).

Statements associating schizophrenia with changes in the phospholipid membrane metabolism, loss of highly polyunsaturated fatty acids from the membranes owing to increased activity of the enzyme phospholipase A2, have been widely addressed in the schizophrenia literature (Horrobin, 1998; 1999). Horrobin has proposed that the membrane lipid abnormalities that can be present in schizophrenia can also result in dyslexia, bipolar disorder and high creativity (Horrobin, 1998), but it still remains a mystery how exactly phospholipid metabolism abnormalities may lead to creative output.

Folley and collegues (2003) suggested, having their preliminary data as a basis, that the dysregulation of phospholipids metabolism (either too much or too little) may lead to psychosis-like states and creativity (Folley, Doop, \& Park, 2003).

Differences in noradrenergic functioning during creative problem-solving, are being tested by the researchers in order to reach to more solid outcomes in the Biological fiels of this issue (Chatterton, Vogelsong, Lu, Ellman, \& Hudgens, 1996).

The findings in this field suggest differences in populations associated with creativity, levels of schizotypy, and phospholipids metabolism. However no consistent results were found yet.

\section{Genetic Research}

Genetic research reveals a link between creativity and proneness to psychosis through recent demonstration of a polymorphism of the promoter region of NRG1 (the neuregulin-1) gene (Mei \& Xiong, 2008).

NRG1 SNP's (single nucleotide polymorphisms) SNP8NRG243177 and SNP8NRG221533 are associated with lower FA in the left anterior thalamic radiation and axonal myelination and migration (Sprooten et al., 2009). On one hand, these features are associated with creativity in people with high academical performed (Keri, 2009). On the other hand, the cited polymorphism in NRG1 has been found to predict higher risk of schizophrenia (Stefansson et al., 2002; Stefansson et al., 2003) and bipolar disorder (Thomson et al., 2007). 


\section{The Vulnerability Model}

In order to explain the nature of the relationship between creativity and psychopathology, a model of shared vulnerability was proposed and has gaining support from many fields of knowledge.

The premise of this model is that "the biological determinants conferring risk for psychopathology interact with protective cognitive factors to enhance creative ideation" (Carson, 2011). According to this model, vulnerability elements such as neural hyperconnectivity, a novelty seeking thinking style and cognitive disinhibition, which allows more stimuli into conscious awareness, interacts with cognitive protective features. These protective factors such as high IQ, increased cognitive flexibility and working memory capacity able the person to increase the ability to have various stimuli at consciousness at the same time and make new associations among them.

\section{Conclusions}

A connection between creativity and psychopathology in what concerns to bipolar disorder, schizophrenic disorder as well as squizotypal disorder, has been suggested by the ongoing research on the fields of biology, imagiology, genetic as well as psychometric and psychodiagnostic (mainly the last two). Nevertheless, comparison between studies is difficult due to different definitions and methods used. Besides there is also a need for integration of findings in the different research areas mentioned, in order to reach more accurate conclusions.

\section{References}

Abraham, A., Windmann, S., Daum, I., \& Güntürkün, O. (2005). Conceptual expansion and creativity imagery as a function of psychoticism. Conscious. Cogn., 14, 520-534. doi: 10.1016/j.concog.2004.12.003

Acar, S., \& Runco, M. A. (2012). Psychoticism and creativity: A meta-analytic review. Psychol. Aesthet. Crea. Arts, 6, 341-350. doi: $10.1037 / \mathrm{a} 0027497$

Andreasen, N. C. (1987). Creativity and mental illness: Prevalence rates in writers and their first-degree relatives. Am. J. Psychiatry, 144, 1288-1292.

Barrantes-Vidal, N. (2004). Creativity and madness revisited from current psychological perspectives. J. Conscious. Stud., 11, 58-78.

Barrantes-Vidal, N. (2014). Creativity and the spectrum of affective and schizophrenic psychoses. In J. C. Kaufman (Ed.), Creativity and mental illness (pp. 169-204). Cambridge: Cambridge University Press.

Bartlett, M., \& Davis, G. A. (1974). Do the Wallach and Kogan tests predict real creative behavior? Perceptual and Motor Skills, 39,730 .

Bekhtereva, N. P., Starchenko, M. G., Klyucharev, V. A., Vorob'ev, V. A., Pakhomov, S. V., \& Medvedev, S. V. (2000). Study of the brain organization of creativity: II. Positron-emission tomography data. Human Physiology, 26, 516-522.

Carlsson, I., Wendt, P. E., \& Risberg, J. (2000). On the neurobiology of creativity: Differences in frontal activity between high and low creative subjects. Neuropsychologia, 38, 873-885.

Carson, S. H. (2011). Creativity and psychopathology: A shared vulnerability model. Can. J. Psychiatry, 56(3), 144-153.

Chatterton, R. T. Jr., Vogelsong, K. M., Lu, Y. C., Ellman, A. B., \& Hudgens, G. A. (1996). Salivary alpha-amylase as a measure of endogenous adrenergic activity. Clin. Physiol., 16, 433-448.

Claridge, G., \& Blakey, S. (2009). Schizotypy and affective temperament: Relationships with divergent thinking and creativity styles. Pers. Individ. Dif., 46, 820-826. doi:10.1016/j.paid.2009.01.015

Claridge, G., \& Broks, P. (1984). Schizotypy and hemisphere function I. Personality and Individual Differences, 5, 633-648.

Folley, B. S., Doop, M. L., \& Park, S. (2003). Psychoses and creativity: Is the missing link a biological mechanism related to phospholipids turnover? Prostaglandins Leukot Essent Fatty Acids, 69(6), 467-476.

Fink, A., Benedek, M., Unterrainer, H. F., Papousek, I., \& Weiss, H. M. (2014). Creativity and psychopathology: Are there similar mental processes involved in creativity and in psychosis-proneness? Frontiersin, 5, 1211.

Fink, A., Slamar-Halbedl, M., Unterrainer, H. F., \& Weiss, E. (2012). Creativity: Genius, madness, or a combination of both? Psychol. Aesthet. Crea. Arts, 6, 11-18. doi:10.1037/a0024874 
Fink, A., Weber, B., Koschutnig, K., Benedek, M., Reishofer, G., Ebner, F. et al. (2014). Creativity and schizotypy from the neuroscience perspective. Cogn. Affect. Behav. Neurosci., 14, 378-387.

Folley, B. S., \& Park, S. (2005). Verbal creativity and schizotypal personality in relation to prefrontal hemispheric laterality: A behavioral and near-infrared optical imaging study. Schizophr Res., 80(2-3), 271.

Guilford, J. P. (1959). Traits of creativity. In H. H. Anderson, \& M. S.University (Eds.), Creativity and its cultivation, addresses, Presented at the Interdisciplinary Symposia on Creativity (1st ed., pp. 142-161), Michigan State University, Harper, East Lansing, Michigan, New York.

Haznedar, M. M., Roversi, F., Pallanti, S., Baldini-Rossi, N., Schnur, D. B. et al. (2005). Fronto-thalamo-striatal gray and white matter volumes and anisotropy of their connections in bipolar spectrum illnesses. Biological Psychiatry, 57, 733-742.

Horrobin, D. F. (1998). Schizophrenia: The illness that made us human. Med. Hypotheses, 50, 269-288.

Horrobin, D. F. (1999). The effects of antipsychotic drugs on membrane phospholipids: A possible novel mechanism of action of clozapine. In M. Peet, I. Glen, \& D. F. Horrobin (Eds.), Phospholipid spectrum disorder in psychiatry (pp. 113-117). Carnforth, Lancashire, UK: Marius Press.

Jamison, K. R. (1989). Mood disorders and patterns of creativity in British writers and artists. Psychiatry, 52, 125-134.

Jamison, K. R. (1995). Manic-depressive illness and creativity. Sci. Am., 272, 62-67.

Jamison, K. R. (1989). Mood disorders and patterns of creativity in British writers and artists. Psychiatry, 52, 125-134.

Juda, A. (1949). The relationships between highest mental capacity and psychic abnormalities. Am. J. Psychiatry, 106, $296-304$.

Jung, R. E. (2014). Evolution, creativity, intelligence, and madness: "Here Be Dragons". Frontiers in Psychology, July, 2014, Volume 5, Article 784.

Jung, R. E., Grazioplene, R., Caprihan, A., Chavez, R. S., \& Haier, R. J. (2010). White matter integrity, creativity and psychopathology: Disentangling constructs with diffusion tensor imaging. PLoSONE 5, e9818.

Karlsson, J. L. (1984). Creative intelligence in relatives of mental patients. Hereditas, 100, 83-86.

Karlsson, J. L. (1970). Genetic association of giftedness and creativity with schizophrenia. Hereditas, 66, 177-182.

Karlsson, J. L. (2001). Mental abilities of male relatives of psychotic patients. Acta Psychiatr. Scand, 104, 466-468.

Keri, S. (2009). Genes for psychosis and creativity: A promoter polymorphism ofthe neuregulin 1 gene is related to creativity in people with high intellectual achievement. Psychol. Sci., 20, 1070-1073.

Kyaga, S., Landén, M., Boman, M., Hultman, C. M., Långström, N., \& Lichtenstein, P. (2013). Mental illness, suicide and creativity: 40-year prospective total population study. J. Psychiatr Res., 47(1), 83-90.

McIntosh, A. M., Maniega, S. M., Lymer, G. K., McKirdy, J., Hall, J. et al. (2008). White matter tractography in bipolar disorder and schizophrenia. Biol Psychiatry, 64, 1088-1092.

Mednick, S. A. (1962). The associative basis of the creative process. Psychological Review, 69, 220-232.

Mei, L., \& Xiong, W. C. (2008). Neuregulin 1 in neural development, synaptic plasticityand schizophrenia. Nat. Rev. Neurosci., 9 , 437-452.

Nelson, B., \& Rawlings, D. (2010). Relating schizotypy and personality to the phenomenology of creativity. Schizophr. Res., 36, 388-399.

Nettle, D. (2006). Schizotypy and mental health amongst poets, visual artists, and mathematicians. J. Res. Pers., 40, 876-890. doi: 10.1016/j.jrp.2005.09.004

Reddy, R., \& Yao, J. K. (1999). Membrane-protective strategies in schizophrenia: Conceptual and treatment issues. In M. Peet, I. Glen, \& D. F. Horrobin (Eds.), Phospholipid spectrum disorder in psychiatry (pp. 75-88). Cransforth, Lancashire, UK: Marius Press.

Simonton, D. K. (2013). Creative thought a sblind variation and selective retention: Why creativity is inversely related to sightedness. J. Theor. Philos. Psychol., 33, 253-266.

Sprooten, E., Lymer, G. K., Maniega, S. M., McKirdy, J., Clayden, J. D. et al. (2009). The relationship of anterior thalamic radiation integrity to psychosis risk associated neuregulin-1 variants. Mol. Psychiatry, 14, 237-238, 233.

Stefansson, H., Sigurdsson, E., Steinthorsdottir, V., Bjornsdottir, S., Sigmundsson, T. et al. (2002). Neuregulin 1 and susceptibility to schizophrenia. Am. J. Hum Genet, 71, 877-892.

Stefansson, H., Sarginson, J., Kong, A., Yates, P., Steinthorsdottir, V. et al. (2003). Association of neuregulin 1 with schizophrenia confirmed in a Scottish population. Am. J. Hum Genet, 72, 83-87.

Sussmann, J. E., Lymer, G. K. S., McKirdy, J., Moorhead, T. W. J., Maniega, S. M., \& Job, D. (2009). White matter abnormalities in bipolar disorder and schizophrenia detected using diffusion tensor magnetic resonance imaging. Bipolar Disord, 11, 11-18.Thomson, P. A., Christoforou, A., Morris, S. W., Adie, E., Pickard, B. S. et al. (2007). Association of Neuregulin 1 with schizophrenia and bipolar disorder in a second cohort from the Scottish population. Mol. Psychiatry, 12, 94-104. 
Thys, E., Sabbe, B., \& de Hert, M. (2011). Creativity and psychiatric disorders: Recent neuroscientific insights. Tijdschr Psychiatr, 53(12), 905-915.

Thys, E., Sabbe, B., \& De Hert, M. (2012). Creativity and psychiatric disorders: Exploring a marginal area. Tijdschr Psychiatr, 54(7), 413-425.

Torrance, E. P. (1988). The nature of creativity as manifest in 15 testings. In R. J. Sternberg (Ed.), The nature of creativity (pp. 43-75). New York: Cambridge University Press.

Wei, J., Ramchand, C. N., \& Hemmings, G. P. (1992). Studies on concentrations of NA and HVA and activity of DBH in the serum from schizophrenic patients, first-degree relatives and normal subjects. Schizophr. Res., 8, 103-110. 